\title{
Laboratory Vs Field Performance of Innovative Thermal Insulating Plasters
}

\author{
Stefano Fantucci, Elisa Fenoglio and Valentina Serra \\ Politecnico di Torino - Department of Energy, C.so Duca degli Abruzzi 24 Torino, Italy. \\ stefano.fantucci@polito.it
}

\begin{abstract}
Thermal insulating plasters and renders are becoming a popular solution for the energy retrofit of existing and historic buildings because of their suitability/compatibility with the existing masonry supports. However, as for most of the insulating products, the actual performance of these materials might significantly differ from the one determined with simplified methods (EN ISO 6946 standard) that are commonly adopted by the designers. In this study, an overview of the latest Authors researches that involve three different thermal insulating plasters, containing respectively perlite, vegetal and aerogel aggregates, are presented. The developed plasters were characterized in the laboratory and successively applied in three demonstration buildings. From the in-field thermal monitoring activities, all the analysed thermal insulating plasters showed a decrease in the thermal performance between 25 and $30 \%$ if compared to the laboratory measurements.
\end{abstract}

Keywords: Plaster, Render, Aerogel, Retrofit, Historical Buildings.

\section{Introduction}

In the last years the energy demand reduction, and hence, the reduction of greenhouse gas emission has become a crucial global strategy. Building sector can play a key role in this process. Since the largest part of the EU existing buildings is old and thus weak from the thermal point of view, retrofit strategies should be adopted for improving the thermal insulations level. Nevertheless, a big challenge is to identify suitable insulating solutions able to guarantee the proper compatibility with the existing masonries, considering that $\sim 39 \%$ of the EU residential buildings were built before the 1960'. Recently, different retrofit strategies for existing buildings have been developed. Among all the different solutions one of the most promising is represented by the thermal insulating plasters and renders. These materials are similar to the traditional plasters, but the sand is replaced by lightweight thermal insulating aggregates (LWA) to reduce density and thermal conductivity. Key-features of these materials are the ease of application on irregular surface, the higher hygrothermal compatibility, the minimum space reduction (indoor application) and the good thermal performance improvement. Several studies have demonstrated that good thermal performance can nowadays be achieved by using different LWA typologies e.g. vegetal (Cherki A et al., 2014, Mazhoud B. et al., 2016, Brása A. et al., 2013), mineral (Barbero-Barrera M. et al., 2015, Osman G. 2016, Konakova D. et al., 2017), polymeric (Mayor P. et al., 2012, ŠeputytèJucikė J. et al., 2014) or silica aerogel (Ibrahim M. et al., 2014, Stahl T. et al., 2012, Buratti C. et al., 2014, Fantucci S. et al., 2020).

Nevertheless, despite the interesting potentials of thermal insulating plasters, some aspects are currently under investigation. Actually, during their service life, these materials might be exposed to variable boundary conditions e.g. temperature and relative humidity variations, 
that can strongly affect the expected thermal performance. It seems evident that, in addition to the laboratory nominal thermal conductivity measurements, an in-field monitoring activity can be useful.

The aim of this paper is to present a comparison between the laboratory performance and the actual in-field monitored performance, in real case studies. For this sake, an overview of the latest Authors researches that involve the monitoring of three different historical case study buildings in northern Italy in which three different thermal insulating plasters containing different LWA were applied (vegetal, mineral and aerogel) is here presented.

\subsection{The Developed Materials}

The materials hereafter presented were developed adopting different LWA typologies (vegetal, mineral, and aerogel). The plasters were measured in the laboratory to determine the nominal thermal conductivity and then applied and monitored to different case study buildings in north Italy. The first formulation presented (VGT 04) is made by natural hydraulic lime as a binder with addition of vegetal and mineral aggregate, respectively corncobs (33\% in weight) and perlite (10\% in weight); the product was then applied to a historical building located in Turin (Ex Albergo della Virtù, 1580). The second analysed plaster typology (P_30) is made by mineral LWA. The Natural Hydraulic Lime (NHL2) was mixed with cement ( $<7.5 \%$ in weight) and perlite was used as aggregate ( $30 \%$ in weight); the product was applied to a XIX - XX century rural house located in Dogliani (CN).

The last plaster typo weight of granular aerog building located the different materials Fantucci S. et al., 2019)
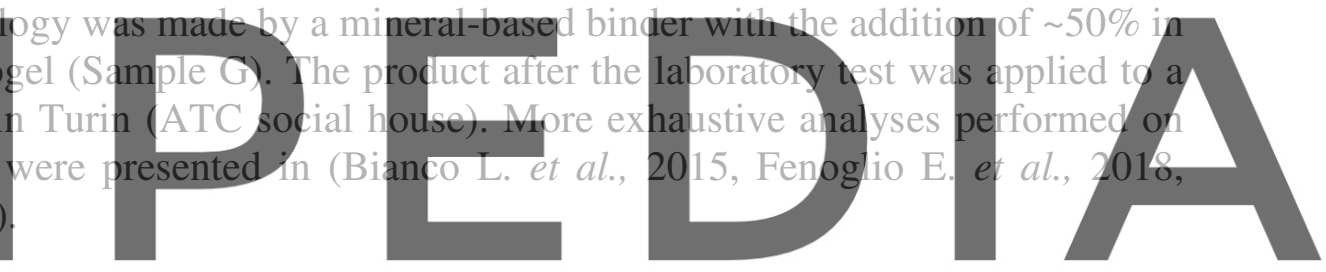

\section{Laboratory Assessment}

Register for free at https//www.scipedia.com to download the version without the watermark Accordingly, to the EN 998-1 standard, the thermal plaster to be classified as "T1" must achieve a $\lambda$-value lower than $0.10 \mathrm{~W} / \mathrm{mK}$. So for this classification, it is essential to experimentally assess the thermal conductivity in laboratory conditions.

\subsection{The Laboratory Analysis}

The procedure to perform the thermal conductivity measurement is reported in EN 12667:2001. The apparatus adopted for the plaster samples presented in this paper is the Heat Flux Meter (HFM Figure 1a). It is made by two flat parallel plates in which the plaster specimen is placed in between. It is possible to set different temperatures of the plates to establish a constant temperature difference $\Delta T$, then the generated specific heat flux $\varphi$ is measured. In this case, a temperature difference between the plates of $10^{\circ} \mathrm{C}$ was set. The HFM collects the surface temperature difference and the heat fluxes until constant conditions are reached, then for known specimen thickness $t$ it is possible to determine the thermal conductivity as follow:

$$
\lambda_{e q}=t \cdot \frac{\varphi}{\Delta T}\left[W \cdot m^{-1} K^{-1}\right]
$$


The tested samples are characterized by a size of $60 \times 60 \times 10 \mathrm{~cm}$ (VGT 04) and of $40 \times 40$ $x 5 \mathrm{~cm}$ (P_30 and G). Before to start the test, the samples were dried in a climatic chamber (ACS DM 340 Figure 1b) until a constant mass was reached. Then to avoid any vapour migration between the samples and the environment, they were sealed in a vapour-tight envelope.
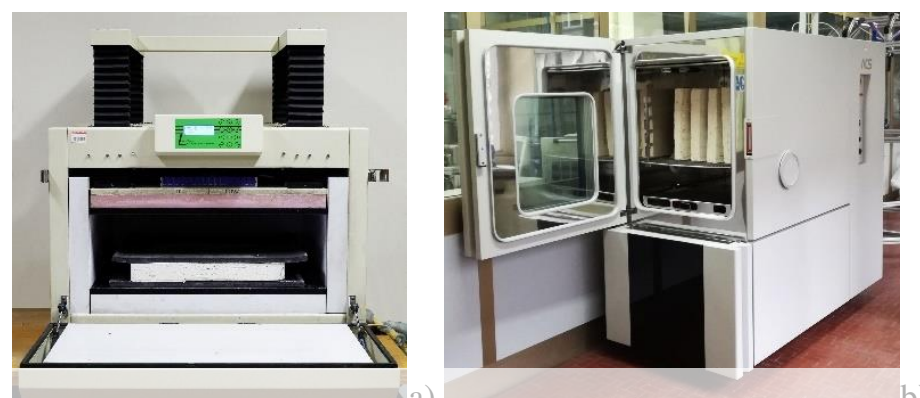

Figure 1. a) the heat flux meter adopted for the measurements (picture from Fantucci et al. 2020); b) the climatic chamber adopted for the material drying.

\subsection{Results}

The thermal conductivity of the thermal plaster formulations is reported in Table 1. Results show that the lower is the thermal conductivity of the LWA added in the formulations, the lower is the density of non super-insulating $\mathrm{W} / \mathrm{mK}$ ) can be achiev

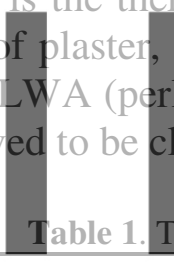

Sample

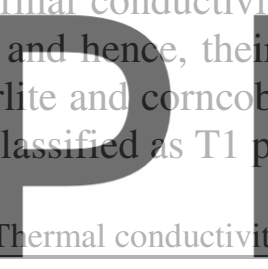

$\mathrm{P}$

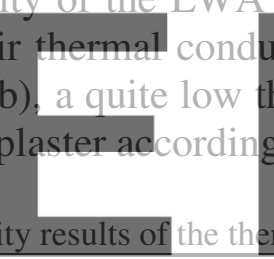

$\lambda_{10 \mathrm{dry}}[\mathrm{W} / \mathrm{mK}]$

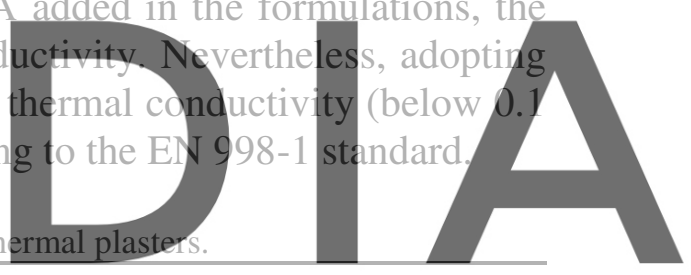

Results from

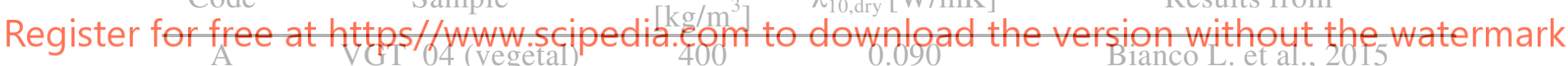

\begin{tabular}{ccccc}
\hline B & P_30 (perlite) & 394 & 0.084 & Fenoglio E. et al., 2018 \\
\hline C & Sample G (aerogel) & 134 & 0.027 & Fantucci S. et al., 2020 \\
\hline
\end{tabular}

\section{In-situ Monitoring}

In addition to the laboratory thermal conductivity measurement, an in-field monitoring campaign was carried out for the three different thermal plaster formulations.

\subsection{Demonstration Buildings}

For each formulation, a different case study building was selected for the material installation. The monitoring phase aims at analysing the actual in-field thermal performance and to compare it with the laboratory measurements. For each case study, two identical walls with the same orientation were selected: one was kept as reference wall while the other was retrofitted with the thermal insulating plasters applied on the internal side of the wall.

The plaster A (vegetal-based) was applied at "Ex Albergo di Virtù" (1580), a historic 
building located in Turin (Figure 2a). The south-east oriented external wall was selected for the application of $6 \mathrm{~cm}$ thick layer of thermal plaster from the interior side. The existing walls are made of a $\sim 50 \mathrm{~cm}$ thick layer of stones and bricks.

The plaster B (perlite-based) was applied in a $5 \mathrm{~cm}$ thick layer for the energy retrofit of a rural building located in Dogliani (CN) (Figure 2b). The selected walls are north-east oriented, and the structure is made up of about $50 \mathrm{~cm}$ layer of solid bricks with an external lime plaster layer.

Finally, a 1920 social house building, located in Turin, and managed by ATC (Agenzia Territoriale Per La Casa del Piemonte Centrale) was chosen as reference building for the application and monitoring of the plaster $\mathrm{C}$ (aerogel-based) (Figure 2c). Two identical solid brick cavity walls south-east oriented were selected, the retrofitted one was coated with $\sim 4.5$ cm plaster layer.

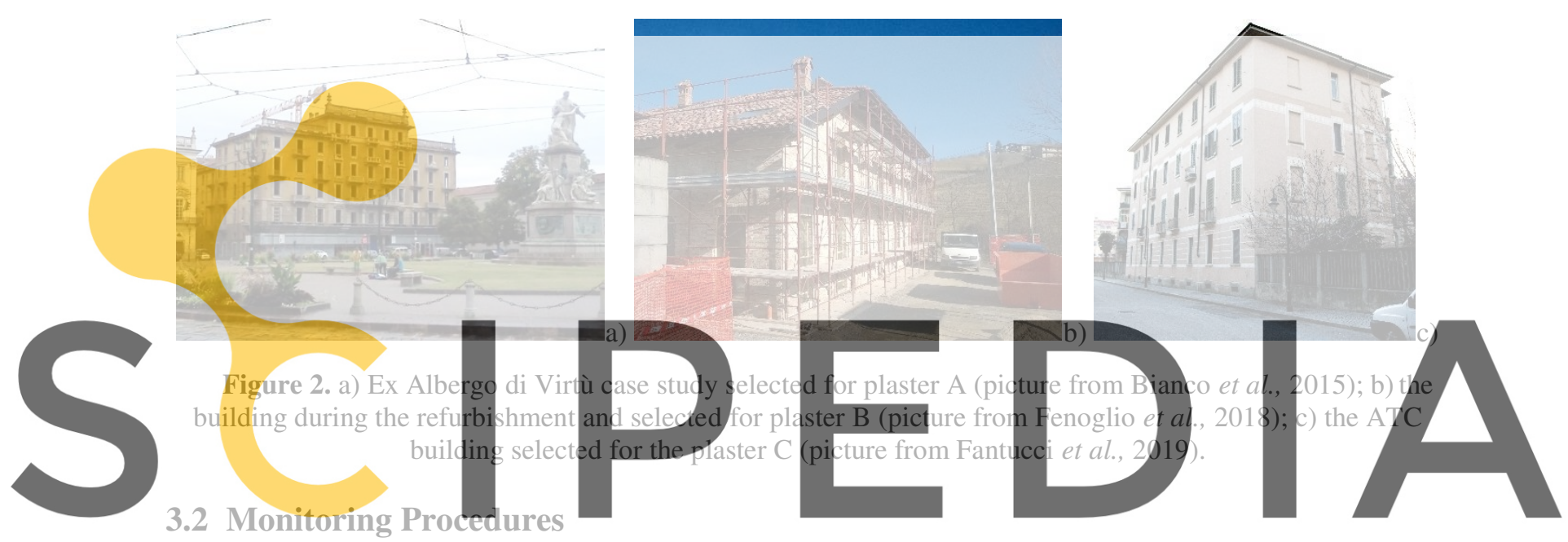

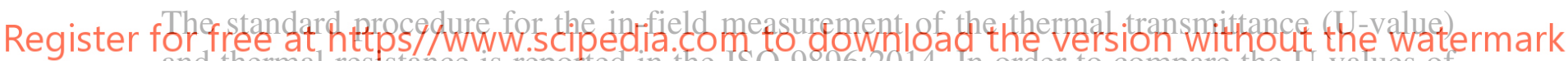
and thermal resistance is reported in the ISO 9896:2014. In order to compare the U-values of the retrofitted and the non-retrofitted walls, the measurements were carried out simultaneously. A preliminary thermographic survey was performed to assure that the wall portion selected for the monitoring was sufficiently uniform and not affected by thermal bridges (Figure 3a). The internal and external air temperature values were measured by means of Type-T thermocouples. Moreover, heat flux plates (HFP01), glued on the inner side of the walls, were used to measure the heat flux densities and then, after at least $72 \mathrm{~h}$ of measurements, to assess the U-value by using the average method described in the ISO 9869 standard. The comparison of the U-values measured in the reference and in the retrofitted walls allowed determining the thermal performance improvement achievable by adopting the thermal insulating plaster. Furthermore, the equivalent thermal conductivity of the thermal insulating plaster layer was calculated according to Eq. (1).

$$
\lambda_{e q}=t /\left(\frac{1}{U_{p l t}}-\frac{1}{U_{\text {ref }}}\right)[W / m K]
$$

Where: $t$ is the plaster layer thickness [m]; $\mathrm{U}_{\text {plt }}$ is the thermal transmittance of the plastered wall $\left[\mathrm{W} / \mathrm{m}^{2} \mathrm{~K}\right]$; $\mathrm{U}_{\text {ref }}$ is the thermal transmittance of the reference wall $\left[\mathrm{W} / \mathrm{m}^{2} \mathrm{~K}\right]$; 
In the different case studies, the measurements were carried out for a period longer than those required by the standard. Moreover, since some façades are south-east oriented, the data adopted for the calculation correspond to the period with low solar radiation and external temperature.

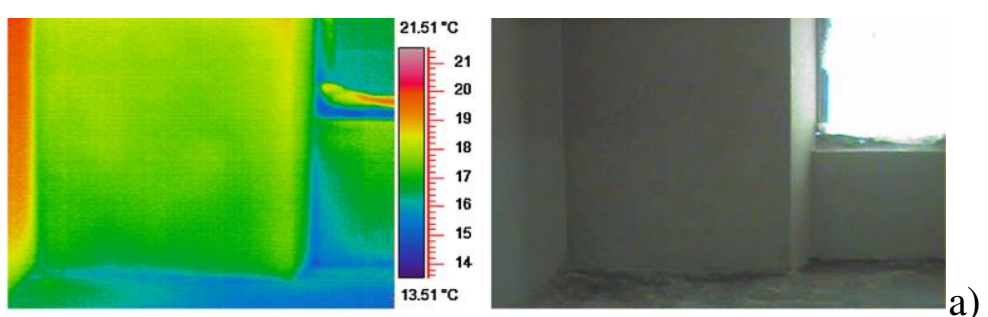

Figure 3. a) a thermographic survey carried out on the Ex Albergo di Virtù (picture from Bianco et al. 2015).

\subsection{Results}

\subsubsection{Results of Plaster A}

Figure 4 report the data of the U-value for the wall retrofitted with the plaster A (vegetalbased). The measurement was performed for 19 consecutive days. The thermal transmittance value achieved at the end of the monitoring period was $0.56 \mathrm{~W} / \mathrm{m}^{2} \mathrm{~K}$. Considering a U-value of about $0.8 \mathrm{~W} / \mathrm{m}^{2} \mathrm{~K}$ (estimated by EN ISO 6946 standard) for the reference wall, a reduction of about $30 \%$ can be underlined. Moreover, the equivalent thermal conductivity of the thermal plaster layer was determined $(\sim 0.116 \mathrm{~W} / \mathrm{mK})$ showed $\mathrm{W} / \mathrm{mK})$. This thermal installed plaster compared to the one tested in the laboratory. worth to be highlighted that the drying process was still and the wall U-value was slightly still decreasing.

Register for free at https//www.scipedia.com to download the version without the watermark

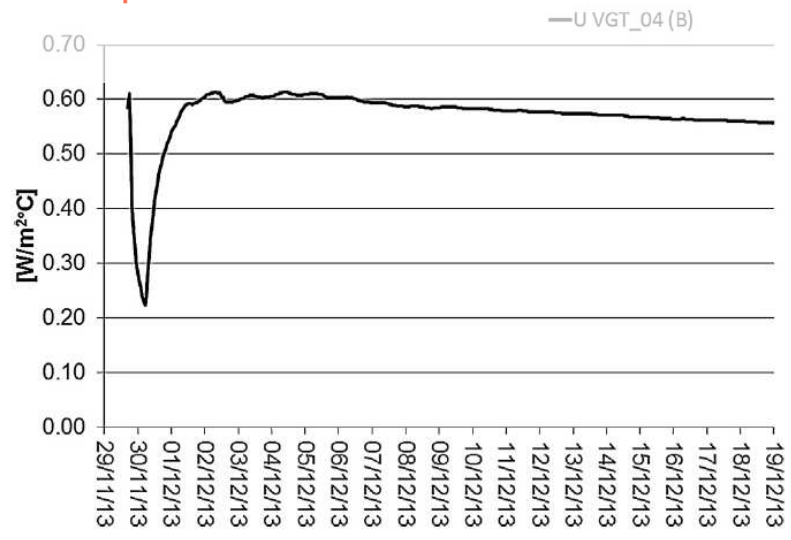

Figure 4. Thermal transmittance measured for the wall retrofitted with the plaster A.

\subsubsection{Results of plaster $B$}

The plastered and bare walls used for the thermal transmittance assessment of plaster B were monitored for 4 days and the results of the monitoring campaign are reported in Figure 5. 
The plastered wall reached a U-value of $\sim 0.80 \mathrm{~W} / \mathrm{m}^{2} \mathrm{~K}$ that is the $45 \%$ lower than the value achieved by the bare wall $\left(\sim 1.43 \mathrm{~W} / \mathrm{m}^{2} \mathrm{~K}\right)$.

The equivalent thermal conductivity calculated for the perlite-based thermal plaster reached a value $\sim 0.092 \mathrm{~W} / \mathrm{mK}$ that is $\sim 10 \%$ higher than the values measured in the laboratory.

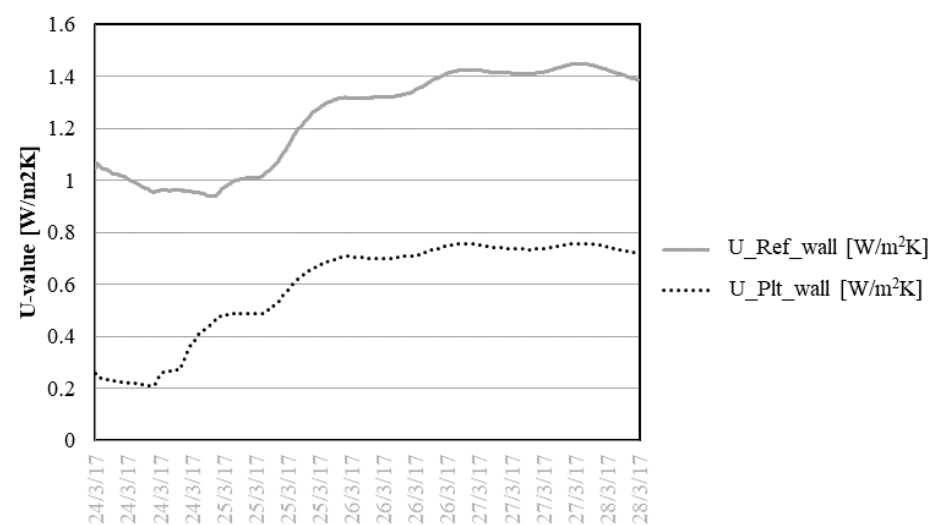

Figure 5. Thermal transmittance measured for the wall retrofitted with the plaster B.

\subsubsection{Results of Plaster C}

The aerogel-based plaster was monitored for more than one month. However, only one reference week was selected for the analysis because of the more suitable boundary conditions. Thermal transmittance values for both the bare and retrofitted wall were measured and reported in Figure 6. It is noticeable a thermal transmittance reduction of $-60 \%$, inded the reference wall shows a $U$-value of $\sim 0.99 \mathrm{~W} / \mathrm{m}^{2} \mathrm{~K}$ while the retrofitted wall value of $0.42 \mathrm{~W} / \mathrm{m}^{2} \mathrm{~K}$. The thernal conductivity of the plaster layer that was calc the U-values of the two walls, was $\sim 0.033 \mathrm{~W} / \mathrm{mK}$, that was about $17 \%$ higher than the value measured in laboratory conditions.

Register for free at htbps//www.scipedia.com to download the version without the watermark

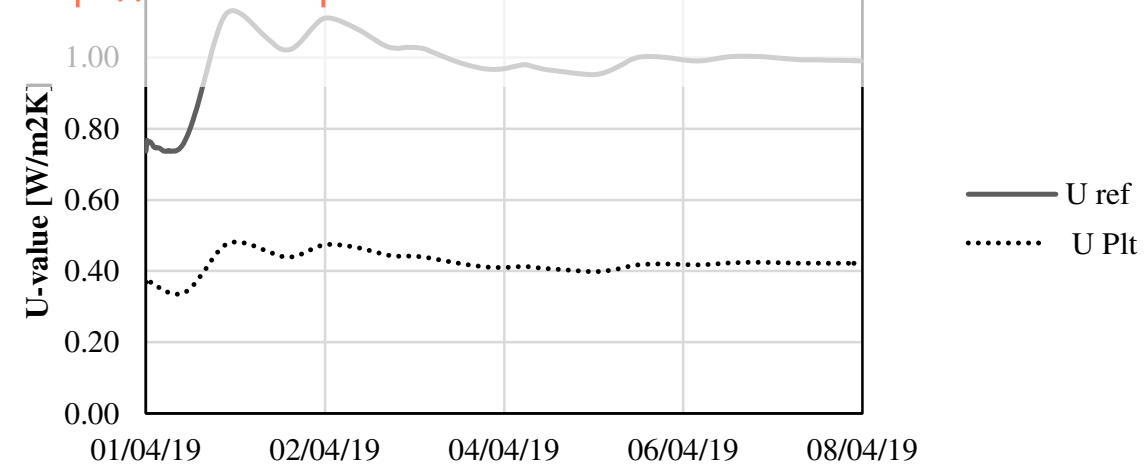

Figure 6. Thermal transmittance measured for the wall retrofitted with the plaster C.

\section{Discussion}

The laboratory tests performed on different thermal insulating plaster samples highlighted, as expected, a decrease of the thermal conductivity due to the addition of lightweight (vegetal, perlite and aerogel) aggregates in the formulations. 
The in-situ measurements performed for the vegetal based plaster ( $60 \mathrm{~mm}$ thick layer) have shown a decreasing of the U-value of about $30 \%$ respect to the non-retrofitted wall. Nevertheless, for this case study, it should be highlighted that the measurement was carried out when the material was still losing moisture. The perlite-based plaster shows a reduction of the U-value of about $45 \%$ ( $\sim 50 \mathrm{~mm}$ thick layer). As expected, the plasters with a lower thermal conductivity (aerogel-based) allowed the achievement of the higher thermal transmittance reduction, up to $60 \%$ with a thinner layer $(\sim 45 \mathrm{~mm})$. Comparing the nominal thermal conductivity values measured in the laboratory with the actual equivalent thermal conductivity determined through the monitoring campaign, an increment between $10 \%$ and $30 \%$ was highlighted a slight decrease in the thermal performance.

This performance decrease can be mainly related to different reasons: i) the high in-field measurement uncertainty; ii) the different drying stage of the three analysed plasters; iii) the different temperature and the higher moisture content of the in-field monitored plaster compared to the laboratory measurements. The latter reason can be explained since the material tested in the laboratory were dried before the test and the measurements were carried out at $10^{\circ} \mathrm{C}$ (mean temperature). Nevertheless, the results demonstrate that the adoption of the thermal insulating plasters are a suitable solution for the energy retrofit of existing buildings.

\section{Conclusions}

The thermal plaster formulations tested in this study were made up of different mineral

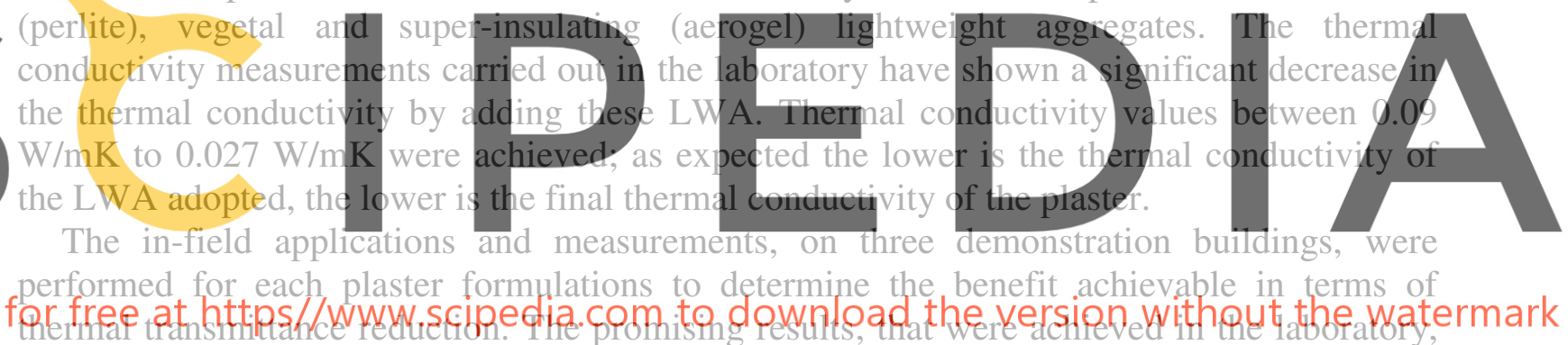

were confirmed by the monitoring campaign: a reduction of thermal transmittance between $30 \%$ to $60 \%$ was measured for the different piaster.

Comparing the nominal thermal conductivity values measured in the laboratory with the actual equivalent thermal conductivity determined through the monitoring campaign, an increment between $10 \%$ and $30 \%$ were highlighted. This decrease of performance was mainly due to higher moisture content and different temperature at which the plasters were exposed.

From these analyses, it is possible to underline that the characterisation of the thermal conductivity at different temperatures and moisture content are necessary to properly evaluate the actual thermal performance and allow more conscious evaluation among different retrofit alternatives.

\section{Acknowledgements}

The research activities have received funding from the project "Wall-ACE" in the framework of EU Horizon 2020 research and innovation programme under the Grant Agreement No. 723574, and SI ${ }^{2}$ - SISTEMI ISOLANTI INNOVATIVI. The authors would also thanks the Italian manufacturer Vimark for provide the materials and the installation on the pilot site, Pollo R., Grosso G., Lubrano F., Bianco L. and Carbonaro. C. 


\section{ORCID}

Stefano Fantucci: http://orcid.org/0000-0001-8535-549X

Elisa Fenoglio: https://orcid.org/0000-0001-8142-6705

Valentina Serra: http://orcid.org/0000-0001-6341-5762

\section{References}

EN 12667 (2001). Thermal performance of building materials and products - Determination of thermal resistance by means of guarded hot plate and heat flow meter methods.

EN 998-1 (2010). Specification for mortar for masonry Part 1: Rendering and plastering mortar

Barbero-Barrera M., García-Santos A. and Neila-González F. (2014). Thermal conductivity of lime mortars and calcined diatoms. Parameters influencing their performance and comparison with the traditional lime and mortars containing crushed marble used as renders, Energy and Buildings.

Bianco, L., Serra, V., Fantucci, S., Dutto, M. and Massolino, M. (2015). Thermal insulating plaster as a solution for refurbishing historic building envelopes: First experimental results, Energy Build. 95 (2015).

Brása A., Goncalves F. and Faustino P. (2013). Cork-based mortars for thermal bridges correction in a dwelling: Thermal performance and cost evaluation, Energy and Buildings.

Buratti C., Moretti E., Belloni E. and Agosti F. (2014). Development of Innovative Aerogel Based Plasters: Preliminary Thermal and Acoustic Performance Evaluation, Sustainability.

Carbonaro C., Tedesco S., Thiebat F., Fantucci S., Serra V. and Dutto M. (2015). An integrated design approach to the development of a vegetal-based thermal plaster for the energy retrofit of buildings, Energy and Buildings.

Cherki A., Remy B., Khabbazi A., Jannot Y. and Baillis D. (2014) Experimental thermal properties characterization of insulating cork-gypsum composite, Construction and Building Materials

Fantucci S., Fenoglio E., Grosso G. Serra V., Perino M.,Marino V. and.Dutto M. (2019). Development of an aerogel-based thermal coating for the energy retr
buildings, Science and Technology for the Built Env
Characterization of High-Performance Aerogel-B
Capozzoli A., Jain L. (eds) Sustainability in En
Technologies, 163. Sptinger.
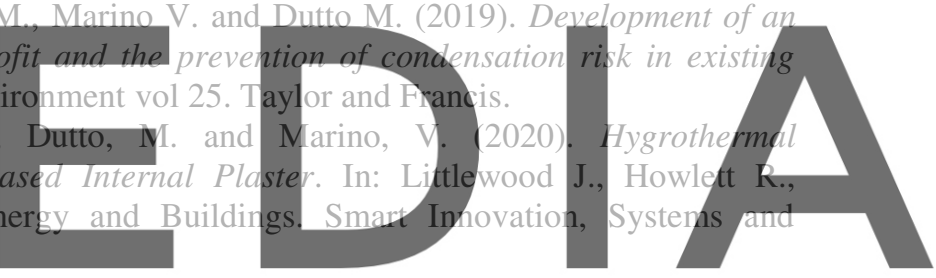

Fenoglio, E., Fantucci, S., Serra, V., Carbonaro, C. and Pollo, R. (2018). Hygrothermal and environmental

rubber from end-of-life tires on mechanical, thermal and acoustic properties of plaster-rubber mortars, Construction and Building Materials.

Ibrahim, M., Wurtz, E., Achard, P. and Biwole, P. H. (2014). Aerogel-based coating for energy efficient building envelopes. 9th International Energy Forum on Advanced Building Skins, Oct 2014, Bressanone, Italy, Proceedings of Energy Forum on Advanced Building Skins, 753-774.

ISO 9869-1 (2014). Thermal insulation - Building elements - in situ measurement of thermal resistance and thermal transmittance - Part 1: Heat flow meter method.

Konakova, D., Cachova, M., Vejmelkova, E., Keppert, M., Jerman, M., Bayer, P., Rovnaníkova, P. and Cerný, R. (2017). Lime-based plasters with combined expanded clay-silica aggregate: Microstructure, texture and engineering properties, Cement and Concrete Composites 83.

Mazhoud, B., Collet, F., Pretot, S. and Chamoin J. (2016). Hygric and thermal properties of hemp-lime plasters, Building and Environment.

Osman, G., Juan Jose, C. D, Mucahit, S., Fuat, K. and Felipe Pedro, Á. R. (2016). A novel lightweight gypsum composite with diatomite and polypropylene fibers, Construction and Building Materials.

Šeputytė-Jucikè, J., Sezeman, G. A., Sinica, M. and Modestas, M. (2014). Impact of granules from crushed expanded polystyrene package on properties of thermoinsulating plaster, Journal of Civil Engineering and Management.

Stahl, T., Brunner, S., Zimmermann, M. and Ghazi Wakili, K. (2012). Thermo-hygric properties of a newly developed aerogel-based insulation rendering for both exterior and interior applications, Energy and Buildings. 